\title{
Patología del epitelio corneal humano en el pénfigo vulgar mediada por anti-desmogleína 3
}

\section{Anti-desmoglein 3-mediated pathology of the human corneal epithelium in pemphigus vulgaris}

\author{
Jeffrey Jones ${ }^{\# 1}$, Ricardo F. Frausto\#2, Shawna Langley ${ }^{1}$, Kelly S. Keefe ${ }^{1}$, Anthony J. Aldave ${ }^{2 *}$ y John Affeldt ${ }^{1}$ \\ ${ }^{1}$ Loma Linda Eye Institute, Centro Médico de la Universidad de Loma Linda, Loma Linda; ${ }^{2}$ Stein Eye Institute, Escuela de Medicina David Geffen, \\ UCLA, Los Angeles. California, Estados Unidos \\ \#Contribuyeron por igual
}

\section{Resumen}

Objetivo: Informar nuevos hallazgos corneales en un individuo diagnosticado con pénfigo vulgar (PV) y demostrar un posible papel de los autoanticuerpos anti-desmogleína 3 (DSG3) en la patología del epitelio corneal. Métodos: Se realizaron exámenes cutáneos y de biomicroscopia con lámpara de hendidura a una mujer afroamericana de 37 años. Para identificar autoanticuerpos anti-DSG, se utilizó una biopsia de una lesión de la mucosa oral y una muestra de suero en varios inmunoensayos. Se midieron los transcritos de DSG en córnea de donante normal, y las proteínas de DSG en córneas tanto de donante como de PV, utilizando qPCR e inmunohistoquímica con fluorescencia (F-IHC), respectivamente. También se realizó F-IHC para determinar la presencia de lgG1 e lgG4 en córneas tanto de donante como de PV. Resultados: El examen clínico reveló erosiones de la mucosa oral e inflamación crónica activa de la superficie ocular con cicatrización corneal superficial significativa en ambos ojos. Se detectaron autoanticuerpos anti-DSG3 en el suero utilizando un ensayo inmunoabsorbente ligado a enzimas. La inmunofluorescencia directa de la biopsia de la lesión de la mucosa oral reveló depósitos intraepidérmicos de inmunoglobulina G lineales/granulares, compatibles con PV. La inmunofluorescencia indirecta del suero del paciente fue negativa, descartando pénfigo paraneoplásico. Se detectaron las cuatro proteínas de DSG en la córnea de un donante normal, mientras que la DSG3 mostró una reducción marcada en la córnea con PV. Se detectó IgG4 en las uniones célula-célula del epitelio corneal en la córnea con PV, lo que coincide con la reducción observada de DSG3. Conclusiones: Aunque el PV afecta principalmente la piel y la mucosa oral, el epitelio corneal también puede verse afectado. En ausencia de cualquier causa secundaria identificable, la patología corneal asociada con PV probablemente está mediada por autoanticuerpos IgG4 dirigidos contra DSG3 en el epitelio corneal.

Palabras clave: Pénfigo vulgar. Desmogleínas. Epitelio corneal. Autoinmunidad.

\section{Abstract}

Purpose: To report novel corneal findings in an individual diagnosed with pemphigus vulgaris (PV), and to demonstrate a potential role for anti-desmoglein 3 (DSG3) autoantibodies in the pathology of the corneal epithelium. Methods: Cutaneous and slit-lamp biomicroscopic examinations were performed on a 37-year-old African American woman. To identify anti-DSG

\section{Correspondencia:}

*Anthony J. Aldave

Stein Eye Institute

100 Stein Plaza, UCLA

Los Angeles, CA 90095-7003, Estados Unidos

E-mail: aldave @ jsei.ucla.edu

Fecha de recepción: 10-12-2018

Fecha de aceptación: 11-03-2019

DOI: 10.24875/RMO.M19000081
Disponible en internet: 01-07-2019 Rev Mex Oftalmol. 2019;93(4):169-177

www.rmo.com.mx 0187-4519/๑ 2019 Sociedad Mexicana de Oftalmología. Publicado por Permanyer México. Este es un artículo Open Access bajo la licencia CC BY-NC-ND (http://creativecommons.org/licenses/by-nc-nd/4.0/). 
autoantibodies an oral mucosal lesion biopsy and a serum sample were used in several immunoassays. DSG transcripts in normal donor cornea, and DSG proteins in both donor and PV corneas, were measured using $q P C R$ and fluorescence-immunohistochemistry $(F-I H C)$, respectively. F-IHC was also performed to determine the presence of IgG1 and IgG4 in both donor and PV corneas. Results: Clinical examination revealed oral mucosal erosions and active, chronic ocular surface inflammation with significant superficial corneal scarring in both eyes. Anti-DSG3 autoantibodies were detected in the serum using an enzyme-linked immunosorbent assay. Direct immunofluorescence of oral mucosal lesion biopsy revealed intraepidermal linear/granular immunoglobin $G$ deposits, consistent with PV. Indirect immunofluorescence of the patient's serum was negative, ruling out paraneoplastic pemphigus. All four DSG proteins were detected in normal donor cornea, while DSG3 showed a marked reduction in PV cornea. IgG4 was detected at the corneal epithelial cell-cell junctions in the PV cornea, which coincides with the observed reduction of DSG3. Conclusions: Although PV primarily involves the skin and oral mucosa, the corneal epithelium may also be affected. In the absence of any identifiable secondary cause, corneal pathology associated with PV is most likely mediated by IgG4 autoantibodies directed against DSG3 in the corneal epithelium.

Key words: Pemphigus vulgaris. Desmogleins. Corneal epithelium. Autoimmunity.

\section{Introducción}

El pénfigo es una enfermedad dermatológica ampollosa rara caracterizada por ampollas cutáneas fláccidas y/o ulceraciones de las membranas mucosas causadas por una reacción autoinmune dirigida contra la familia de proteínas desmogleína presente en los desmosomas de las uniones celulares epiteliales ${ }^{1,2}$. Los tres tipos principales de pénfigo incluyen el pénfigo vulgar (PV), el pénfigo foliáceo (PF) y el pénfigo paraneoplásico (PPN). Cada subtipo de pénfigo tiene una presentación clínica única que corresponde con su perfil específico de autoanticuerpos. El pénfigo vulgar es, con mucho, el subtipo más común de pénfigo y es causado por los autoanticuerpos contra desmogleína 1 (DSG1) y desmogleína 3 (DSG3)². La mayoría de los individuos con PV muestran afectación tanto mucosa como cutánea, pero se puede observar una enfermedad aislada de la mucosa. El pénfigo foliáceo tiene un curso de la enfermedad más leve que el PV, con ampollas limitadas a la piel, y se asocia con autoanticuerpos solamente contra DSG1 $1^{3,4}$. El pénfigo paraneoplásico generalmente se presenta con hallazgos cutáneos variables, afectación grave de las mucosas y una neoplasia maligna interna asociada, en la mayoría de los casos con linfoma no Hodgkin. Los autoanticuerpos del PPN se unen a DSG1, DSG3 y a las proteínas hemidesmosomales de la unión dermoepidérmica ${ }^{5,6}$. El PPN se puede distinguir del PV mediante inmunofluorescencia directa e indirecta, que muestra anticuerpos localizados tanto en los desmosomas epidérmicos como en los hemidesmosomas de la unión dermoepidérmica ${ }^{5}$.

La afectación ocular es una manifestación infrecuente del PV, reportada en solo $7-26 \%$ de los casos ${ }^{2,7,8}$. Cuando se manifiesta, el hallazgo ocular más común es una conjuntivitis bilateral no cicatricial2,7,9-11. La afectación corneal se ha descrito como extremadamente rara, con solo 3 casos identificados en la literatura revisada por pares antes de 2014 ${ }^{12-14}$. En 2014, Chirinos-Saldana y colaboradores publicaron una serie de 15 casos de PV que demostraron cambios en la córnea ${ }^{15}$. Sin embargo, se debe tomar en cuenta que este grupo fue inusual, ya que solo dos pacientes tenían manifestaciones extraoculares de PV, y muchos tenían condiciones sistémicas generadoras de confusión o estaban recibiendo medicamentos potencialmente asociados con cambios en la córnea ${ }^{15}$. Además, ninguno de los informes previos de afectación ocular en el PV confirmó la afectación directa de la córnea al intentar identificar a DSG1 o DSG3 en el epitelio corneal, o la presencia de autoanticuerpos corneales contra estas desmogleínas ${ }^{12-15}$. Por lo tanto, informamos el involucro primario de la córnea en el PV, confirmado mediante la demostración de una colocalización aparente de DSG3 e inmunoglobulina G4 en el epitelio corneal de un individuo afectado.

\section{Propósito}

Informar nuevos hallazgos corneales en un individuo diagnosticado con PV y describir un posible papel de los autoanticuerpos anti-desmogleína 3 (DSG3) en la patología asociada con PV del epitelio corneal. Estos hallazgos pueden proporcionar un mecanismo fisiopatológico para la presentación clínica distintiva que se manifiesta en este caso. Además, informamos la expresión de genes y proteínas de las desmogleínas (DSG1-4) en el epitelio corneal.

\section{Métodos}

Se cumplieron los principios de la Declaración de Helsinki para el tratamiento del individuo informado en 
Tabla 1. Cebadores (primers) utilizados en reacción en cadena de la polimerasa (PCR) cuantitativa

\begin{tabular}{|l|l|l|l}
\hline Gen & ID del banco de cebadores & Forward $\left(5^{\prime}-3^{\prime}\right)$ & Reverse $\left(5^{\prime}-3^{\prime}\right)$ \\
\hline DSG1 & $119703743 c 2$ & AACCCAATCGCCAAAATTCACT & ACCTCTCGATCAACTATGGATGT \\
\hline DSG2 & $189181754 \mathrm{c} 2$ & TTGTTGGGTCTGTTGAAGAGTTG & TTCAGGGTATTGGGCTCATCT \\
\hline DSG3 & $119964717 \mathrm{c} 1$ & GCAAAAACGTGAATGGGTGAAA & TCCAGAGATTCGGTAGGTGATT \\
\hline DSG4 & $197313786 \mathrm{c} 1$ & CAGCCTGTCGAGAAGGAGAG & CCCTACTCCAGAAATCCGGTAT \\
\hline GAPDH & N/A & CGACCACTTTGTCAAGCTCA & AGGGGTCTACATGGCAACTG
\end{tabular}

este estudio. La aprobación del estudio se obtuvo de la Universidad de California, Los Ángeles (UCLA IRB \#11-000020).

\section{Exploración clínica}

Una mujer afroamericana de 35 años de edad se presentó en la clínica de dermatología del Centro Médico Regional del Condado de Riverside (RCRMC, Riverside County Regional Medical Center). Uno de los autores (S.L.) realizó un examen cutáneo estándar. Posteriormente, el paciente fue remitido a la Clínica de Ojos de la Universidad de Loma Linda, donde dos de los autores (J.J. y J.A.) realizaron un examen biomicroscópico con lámpara de hendidura.

\section{Pruebas diagnósticas de laboratorio}

Después de obtener el consentimiento informado, se extrajo una muestra de sangre periférica y una biopsia de la lesión de la mucosa. Se aisló el suero del plasma y se envió al Laboratorio diagnóstico del RCRMC, donde se realizó un ensayo inmunoabsorbente ligado a enzimas (ELISA) para la detección de autoanticuerpos anti-DSG3. Para descartar pénfigo paraneoplásico, el suero también se sometió a inmunofluorescencia indirecta (IFI) utilizando epitelio de vejiga de rata como sustrato ${ }^{6}$. También se realizó inmunofluorescencia directa (IFD) utilizando anticuerpos contra los isotipos de inmunoglobulinas en la muestra de la biopsia de mucosa oral.

\section{Histopatología}

Después de realizar una queratoplastia penetrante en el paciente, el botón corneal se fijó en formalina tamponada al $10 \%$ y se envió al Laboratorio de Patología del Centro Médico de la Universidad de Loma Linda para su procesamiento. Posteriormente, el tejido se incluyó en parafina, se seccionó y se tiñó con hematoxilina y eosina utilizando un protocolo de tinción histológica estándar.

\section{Aislamiento de ARN total y síntesis de ADN complementario}

Se obtuvieron catorce córneas de nueve donantes de bancos de ojos asociados con el consorcio Vision Share de bancos de ojos. Para las córneas del banco de ojos de donantes con una historia ocular sin complicaciones confirmada, se disoció el epitelio corneal enzimáticamente (Dispasa II, Roche, Basilea, Suiza) y se separó la membrana de Descemet. Las córneas sin epitelio y endotelio fueron procesadas para fibroblastos estromales. Las tres capas corneales se homogeneizaron en TriReagent (Life Technologies, Carlsbad, CA), que es una solución que contiene tiocianato de guanidina/fenol, y se aisló el ARN total según las instrucciones del fabricante. Brevemente, después de la homogeneización del tejido en TriReagent, se realizó la separación de fases mediante la adición de cloroformo y centrifugación. La fase acuosa superior que contenía ARN se separó de la fase orgánica inferior que contenía proteínas y ADN, y posteriormente el ARN se precipitó y se purificó utilizando alcoholes. La preparación del ADN complementario con poli(A)+ a partir de $100 \mathrm{ng}$ de ARN total, se realizó utilizando cebadores oligo(dT) 20 y el sistema de síntesis de primera hebra SuperScript ${ }^{\circledR}$ III (Life Technologies, Carlsbad, CA) según las instrucciones del fabricante.

\section{Reacción en cadena de la polimerasa (PCR) cuantitativa}

Para determinar los niveles del transcrito de desmogleínas 1-4 en los tres tipos principales de células (epiteliales, fibroblastos y endoteliales) de la córnea, se realizó una PCR cuantitativa utilizando oligonucleótidos específicos para el transcrito cuyas secuencias se obtuvieron de la base de datos del Harvard Primer Bank (Tabla 1); http://pga.mgh.harvard.edu/primerbank/index.html) ${ }^{16-18}$. La PCR cuantitativa se realizó utilizando el Master Mix 2x KAPA SYBR FAST qPCR (KAPA 
Tabla 2. Anticuerpos utilizados en inmunohistoquímica

\begin{tabular}{|c|c|c|c|c|c|c|}
\hline Proteína objetivo & Isotipo & $\begin{array}{l}\text { Especie de } \\
\text { inmunógeno }\end{array}$ & Clonalidad & Dilución & Proveedor & $\begin{array}{l}\text { Numero de } \\
\text { catálogo }\end{array}$ \\
\hline \multicolumn{7}{|c|}{ Anticuerpos primarios } \\
\hline $\begin{array}{l}\text { DSG1 } \\
\text { DSG2 } \\
\text { DSG3 } \\
\text { DSG4 } \\
\text { KRT12 } \\
\text { IgG1 } \\
\text { IgG4 }\end{array}$ & $\begin{array}{l}\operatorname{IgG} \text { de ratón } \\
\operatorname{lgG}_{1} \text { de ratón } \\
\operatorname{lgG} \text { de cabra } \\
\lg \text { de cabra } \\
\operatorname{lgG} \text { de conejo } \\
\operatorname{lgG}_{2 \mathrm{ak}} \text { de ratón } \\
\operatorname{lgG}_{3} \text { de ratón }\end{array}$ & $\begin{array}{l}\text { humano } \\
\text { humano } \\
\text { humano } \\
\text { humano } \\
\text { humano } \\
\text { humano } \\
\text { humano }\end{array}$ & $\begin{array}{l}\text { monoclonal } \\
\text { monoclonal } \\
\text { policlonal } \\
\text { policlonal } \\
\text { policlonal } \\
\text { monoclonal } \\
\text { monoclonal }\end{array}$ & $\begin{array}{l}1: 200 \\
1: 100 \\
1: 100 \\
1: 33 \\
1: 33 \\
1: 200 \\
1: 100\end{array}$ & $\begin{array}{l}\text { Millipore } \\
\text { Life Technologies } \\
\text { R\&D Systems } \\
\text { Santa Cruz Biotechnology } \\
\text { Santa Cruz Biotechnology } \\
\text { Thermo Scientific } \\
\text { Thermo Scientific }\end{array}$ & $\begin{array}{l}\text { MABT118 } \\
32-6100 \\
\text { AF1720 } \\
\text { sc-28067 } \\
\text { sc-25722 } \\
\text { MH1013 } \\
\text { MA5-16716 }\end{array}$ \\
\hline \multicolumn{7}{|c|}{ Anticuerpos secundarios conjugados con fluorescencia } \\
\hline$R b-\lg G$ & $\begin{array}{l}\text { IgG de } \\
\text { burro (A488) }\end{array}$ & conejo & policlonal & $1: 500$ & Life Technologies & A-21206 \\
\hline Ms-IgG & $\begin{array}{l}\text { IgG de } \\
\text { burro (A594) }\end{array}$ & ratón & policlonal & $1: 500$ & Life Technologies & A-21203 \\
\hline Gt-lgG & $\begin{array}{l}\text { IgG de } \\
\text { burro (A594) }\end{array}$ & cabra & policlonal & $1: 500$ & Life Technologies & A-21207 \\
\hline
\end{tabular}

Biosystems, Boston, MA) en un volumen de reacción de $10 \mu \mathrm{L}$ colocado en una microplaca de 384 pocillos. Las reacciones se procesaron en el sistema en tiempo real LightCycler 480 (Roche, Basilea, Suiza). Las condiciones de la reacción y el análisis de datos se realizaron según lo descrito previamente ${ }^{19}$. Se calculó la expresión relativa utilizando los niveles de ARNm del gen constitutivo GAPDH y utilizando el método comparativo de $\mathrm{C}_{\mathrm{T}}\left(2^{-\Delta \Delta C} \mathrm{~T}\right)$. Los niveles de expresión relativa se representaron como los valores de $2^{-\Delta C} \mathrm{~T}$. Todos los experimentos de qPCR se realizaron en cuatro réplicas biológicas independientes $(n=4)$.

\section{Detección mediante inmunohistoquímica con fluorescencia de las DSG}

La inmunodetección se realizó utilizando anticuerpos (Tabla 2) dirigidos contra las cuatro DSG, IgG1, IgG4 y KRT12 (biomarcador del epitelio corneal), utilizando un protocolo estándar de inmunohistoquímica. Brevemente, las secciones de muestras control y del paciente fijadas con formalina e incluidas en parafina se desparafinaron y rehidrataron en alcohol, y posteriormente se realizó recuperación enzimática del antígeno (Proteinase K, Sigma Aldrich, St. Louis, MO). Posteriormente, las secciones se bloquearon en PBS + Tween 20 al $0.5 \%$ suplementado con BSA (albumina de suero bovino, por sus siglas en inglés) al $1 \%$ y suero de caballo al $10 \%$. Posteriormente, se incubaron toda la noche con el anticuerpo primario diluido a $5 \mu \mathrm{g} / \mathrm{ml}$ en $125 \mu \mathrm{L}$ de tampón de bloqueo, se lavaron 3x en PBS + Tween 20 al $0.5 \%$ y después se incubaron con el anticuerpo secundario conjugado con fluorescencia (Tabla 2) diluido 1: 500 en tampón de bloqueo; se lavaron $3 x$ en PBS + Tween 20 al $0.5 \%$ seguido de un lavado con PBS, y se montaron con medio de montaje acuoso Vectashield (Vector Laboratories, Inc., Burlingame, CA) que contiene 40, 6-diamidino-2-fenilindol (DAPI). Las imágenes de fluorescencia fueron adquiridas mediante microscopía confocal.

\section{Análisis estadístico}

Se utilizó una prueba t no pareada de dos colas para identificar una diferencia significativa en las medias de los niveles de expresión relativa de ARNm de DSG1-4 en el epitelio en comparación con los niveles presentes en el estroma y el endotelio. Las diferencias en las medias de la expresión génica entre el estroma y el endotelio corneal se consideraron significativas con una $p \leq 0.05$.

\section{Resultados}

\section{Descripción clínica}

Una mujer afroamericana de 35 años se presentó en la clínica oftalmológica del Centro Médico Regional del Condado de Riverside (RCRMC) en 2010, refiriendo ojos rojos con dolor de intensidad variable durante toda su vida, de forma bilateral, asociados con visión borrosa. Se le diagnosticó conjuntivitis alérgica y se trató con éxito (aunque temporalmente) con esteroides tópicos. Desarrolló una dermatitis ampollosa difusa que afectó tanto la piel como la mucosa oral, y fue diagnosticada con PV, que luego se confirmó por la presencia de depósitos de inmunoglobulinas en la mucosa 


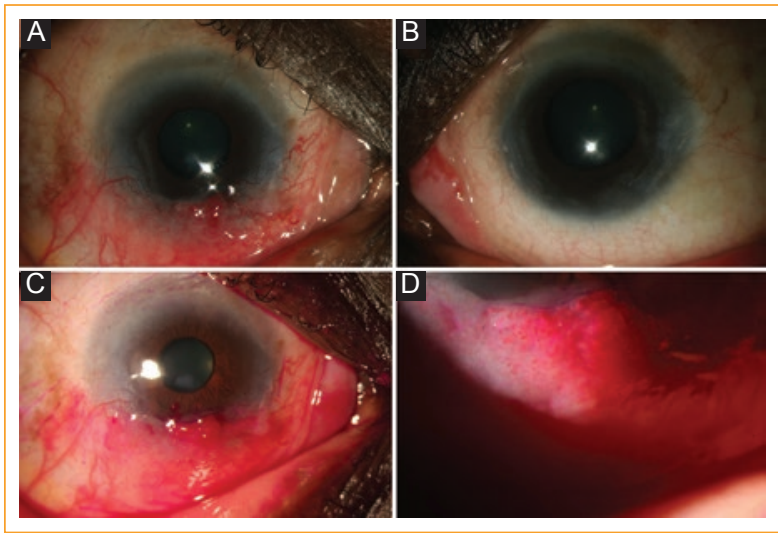

Figura 1. Cambios corneales periféricos en un individuo con pénfigo vulgar. A. Se observó formación de pannus inferior y opacificación corneal periférica 360 grados en el ojo derecho. B. Se observó opacificación corneal periférica sin formación significativa de pannus en el ojo izquierdo. C. Luego de la tinción con rosa de bengala, se visualizaron claramente los bordes del pannus inflamatorio en el ojo derecho. D. La vista a mayor aumento de la región limbal inferior en el ojo derecho, demostró engrosamiento y vascularización prominente del pannus inflamatorio.

oral y autoanticuerpos anti-DSG3 en el suero. Además, la IFI del suero fue negativa y se excluyó PPN. La administración oral de prednisona y azatioprina eliminó las lesiones ampollosas. Posteriormente, experimentó inyección conjuntival variable pero persistente y recurrencias periódicas de las erosiones de la mucosa oral. En última instancia, sufrió una exacerbación aguda de la inflamación ocular y pérdida visual, que no respondió al aumento de la inmunosupresión sistémica. En este momento, fue remitida a la clínica de córnea del RCR$M C$, donde fue evaluada por uno de los autores (J.A.).

En la presentación, la agudeza visual no corregida era de cuenta dedos a nueve pies en el ojo derecho y 20/100 en el ojo izquierdo, mejorando con estenopeico a 20/70 en ambos ojos. El examen con lámpara de hendidura reveló inyección conjuntival bilateral 3+, sin evidencia de erosiones o formación de simbléfaron (Figura 1). Las córneas de ambos ojos mostraban una cicatrización periférica de 360 grados y formación de pannus que se extendía $\sim 2-3 \mathrm{~mm}$ desde el centro (Figura 1A y 1B). En el ojo derecho, se identificó un defecto epitelial paracentral de $\sim 2 \mathrm{~mm} \times 3 \mathrm{~mm}$ (fotos anteriores tomadas después de que se resolvió el defecto epitelial). La córnea derecha también demostró una lesión discreta, inferior, elevada, con bordes, gelatinosa, con vasos en sacacorchos, que parecía cubrir el tejido cicatricial periférico (Figuras 1A, 1C y 1D). Una biopsia descartó extensión

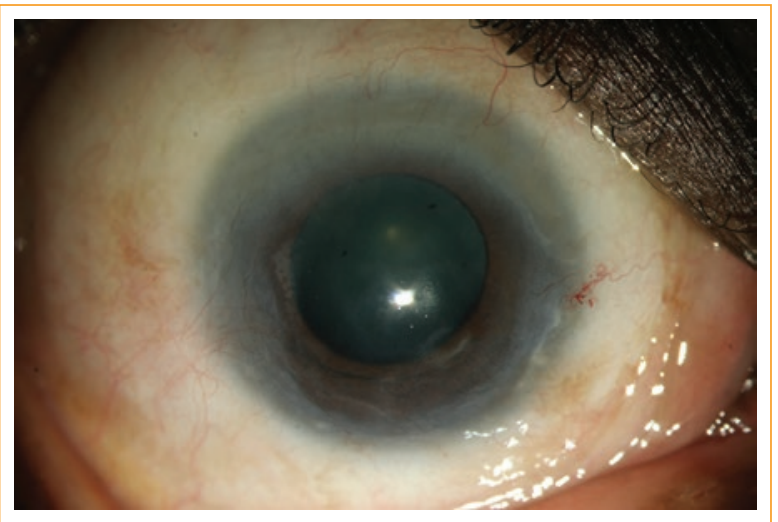

Figura 2. Dos meses después de iniciar el tratamiento con esteroides tópicos, el ojo derecho del individuo con PV mostrado en la Figura 1, demostró resolución del pannus inflamatorio pero persistencia de la cicatrización corneal anterior.

corneal de una neoplasia intraepitelial conjuntival, y se inició un esteroide tópico en ambos ojos. Se logró resolución completa en el ojo derecho, con control de la inflamación en ambos ojos (Figura 2).

La videoqueratografía reveló un astigmatismo irregular significativo de cada córnea, que se supone fue inducido por la cicatrización corneal periférica superficial. Por lo tanto, se realizó una queratectomía superficial en el ojo derecho. Cinco días después del procedimiento, la paciente desarrolló necrosis del estroma corneal que progresó a un gran descemetocele central, que posteriormente se perforó. Cabe destacar que la paciente reveló que había estado usando llevro tópico (suspensión de nepafenaco al $0.3 \%$ ) hasta cinco veces al día desde el momento del raspado de córnea hasta la visita de seguimiento 5 días después, lo que probablemente contribuyó a la necrosis del estroma. Dada la incapacidad de mantener cerrada la perforación durante un período de 15 semanas a pesar de aplicaciones seriadas (5) de cianoacrilato, y con control de las manifestaciones oculares y dermatológicas del PV con esteroides tópicos e inmunosupresión sistémi$\mathrm{ca}$, se realizó una queratoplastia penetrante de $8 \mathrm{~mm}$ de diámetro. Seis meses después de la cirugía, la visión no corregida era de 20/150, y no se observaba evidencia de necrosis estromal recurrente.

\section{Análisis histopatológico de la córnea extirpada}

El examen histopatológico de la córnea extirpada demostró ulceración corneal anterior, inflamación estromal 


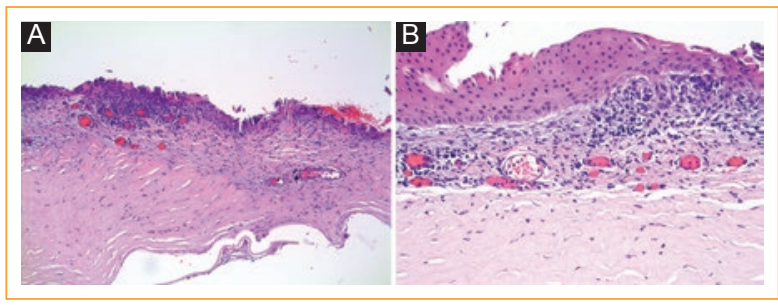

Figura 3. El examen histopatológico de la muestra corneal del individuo con $\mathrm{PV}$, reveló ulceración corneal anterior con infiltrado celular inflamatorio crónico, adelgazamiento estromal y vascularización marcados, y una membrana retrocorneal fibrosa delgada debajo de la membrana de Descemet (tinción con hematoxilina y eosina; aumento 10x) (A). La vista a mayor aumento demostró vasos en el estroma anterior e infiltración de células inflamatorias crónicas (aumento 20x) (B).

crónica, vascularización estromal y tejido fibroso retrocorneal con atrofia de células endoteliales (Figura 3).

\section{Expresión de los genes de DSG en la córnea}

Se determinó la expresión de los genes de DSG en los tres tipos de células predominantes de la córnea mediante qPCR (Figura 4). Las cuatro DSG se expresaron en el epitelio corneal, con una expresión estadísticamente significativamente mayor que en los queratocitos y en las células endoteliales. Se observó una expresión débil de DSG1-3 en queratocitos y de DSG2 en células endoteliales, aunque la detección de cada una estaba en un nivel cercano al límite de detección de la qPCR.

\section{Alteración de la expresión de las proteínas DSG3 y DSG4 en la córnea con PV}

Las cuatro proteínas DSG se detectaron en la córnea de donante sano mediante F-IHQ, demostrando localización en los bordes de las células epiteliales (Figura 5). Mientras que DSG1-3 se detectó en todas las capas del epitelio, DSG4 se localizó en las capas de células epiteliales superficiales. Aunque la expresión de DSG1 y DSG2 no se observó significativamente alterada en el epitelio corneal con PV en comparación con la córnea donante sana, DSG3 y DSG4 demostraron una marcada alteración en su expresión y localización dentro del epitelio corneal con PV. En contraste con el epitelio corneal del donante sano, DSG3 se localizó principalmente en las capas de células epiteliales más superficiales en el caso con PV, y demostró una reducción marcada de su expresión en el resto del epitelio. En comparación con el epitelio corneal donante, la expresión de DSG4 en el epitelio con PV fue difusa y se localizó exclusivamente en el citoplasma de las células epiteliales de la córnea. Si bien se detectó DSG4 en el epitelio corneal donante normal (capas superficiales), es razonable especular que los resultados obtenidos para el epitelio con PV pueden ser un artefacto. No se detectó ninguna de las proteínas DSG en el estroma corneal o el endotelio (datos no mostrados), de acuerdo con los resultados de qPCR. El epitelio corneal también fue positivo para el biomarcador epitelial corneal KRT12, un componente de los filamentos intermedios de tipo I presentes en el citoplasma.

\section{Localización diferencial de las inmunoglobulinas G1 y G4 en la córnea con PV}

Para determinar el tipo de inmunoglobulinas anti-DSG3 que potencialmente median la reducción de la proteína DSG3 en el epitelio corneal con PV, realizamos F-IHQ para los dos tipos de IgG (IgG1 e IgG4) que se asocian más comúnmente con el PV (Figura 6). IgG1 e IgG4 no se detectaron en el epitelio corneal del donante normal. Sin embargo, ambas inmunoglobulinas se detectaron en el epitelio y el estroma de la córnea con PV. Además, estas inmunoglobulinas se detectaron de forma difusa y/o como focos puntiformes dentro del estroma anterior, donde se asociaron con la neovasculatura, e IgG4 mostró focos fluorescentes más numerosos. Aunque ambas inmunoglobulinas se detectaron en el estroma, solo la lgG4 se localizó en los contactos célula-célula en el epitelio, reflejando el patrón de expresión observado para las DSG y asociada con la reducción marcada en los niveles de DSG3.

\section{Discusión}

Las desmogleínas son un pequeño grupo de proteínas que son miembros de la superfamilia de las cadherinas, y junto con las desmocolinas, son un componente importante de los desmosomas, que están involucrados en la adhesión celular ${ }^{20}$. La expresión corneal de las desmogleínas se ha examinado previamente, principalmente en modelos animales, y los estudios iniciales se han limitado a estudiar principalmente a DSG1 ${ }^{21-28}$. Investigaciones más recientes han descrito la expresión de proteínas DSG en el tejido corneal humano, pero a menudo solo han investigado la expresión de una proteína $\mathrm{DSG}^{29-33}$. En conjunto, estos estudios han proporcionado 

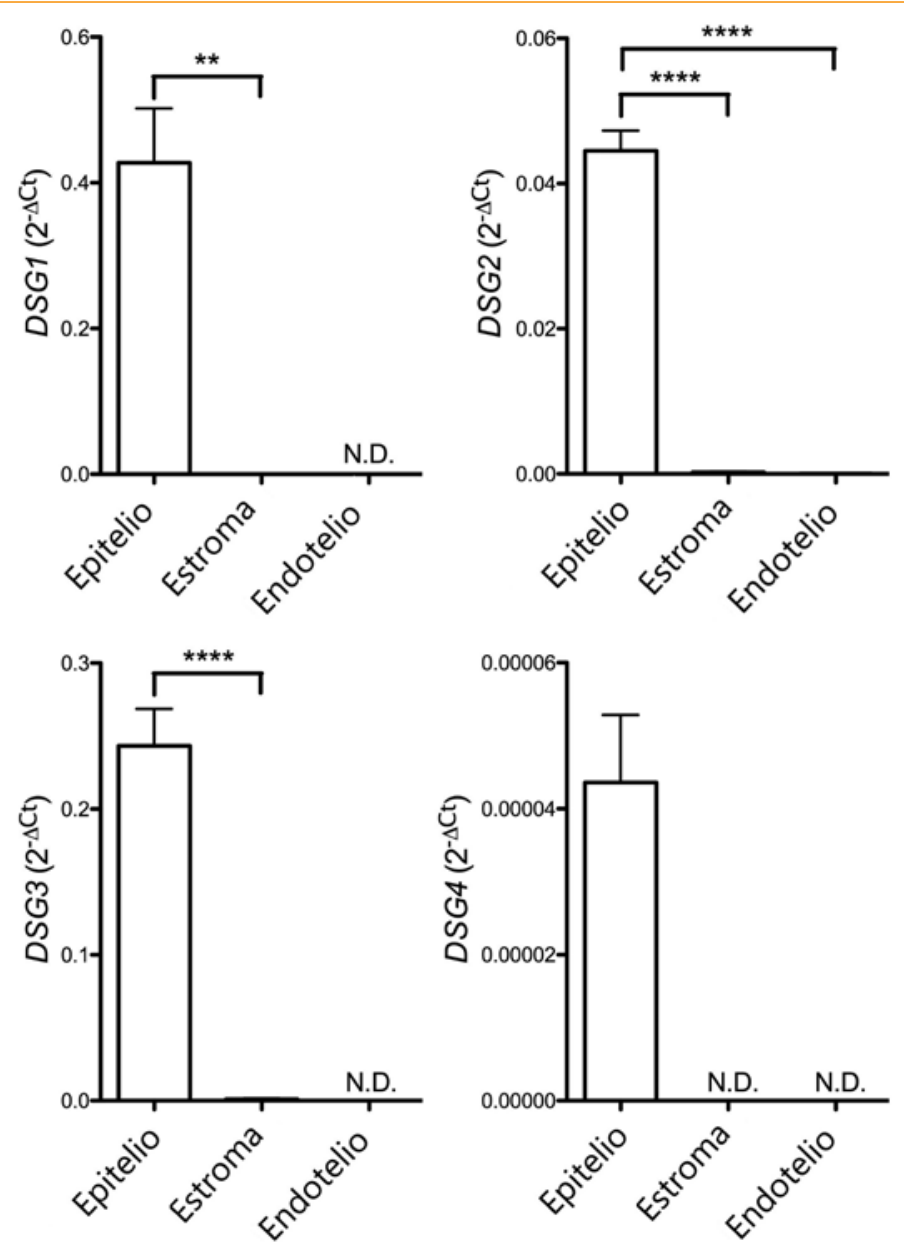

Figura 4. Medición de los niveles de transcritos de DSG en la córnea utilizando qPCR. Los transcritos para DSG 1-4 se expresaron en el epitelio a niveles significativamente más altos que en el estroma y el endotelio. La expresión relativa se representó como ${ }^{-\triangle C}$ T, con el transcrito de GAPDH como gen de referencia para calcular la expresión relativa. El análisis estadístico se realizó utilizando una prueba t no pareada $(n=4)$.

${ }^{* *} \mathrm{p} \leq 0.01 ;{ }^{* * *} \mathrm{p} \leq 0.001 ;{ }^{* * *} \mathrm{p} \leq 0.0001$ (barras de error = SEM). N.D.: no detectado.

evidencia de la expresión de DSG3 en el epitelio corneal humano, sin evaluación específica de la expresión de DSG1, DSG2 y DSG429,33. Demostramos que DSG1-4 se expresan en el epitelio corneal humano, que DSG1-3 están presentes en la mayoría de las capas de células epiteliales, y que DSG4 se expresa solamente en las capas de células epiteliales superficiales.

Está bien documentado en la literatura que DSG3 es la principal cadherina desmosomal involucrada en el $\mathrm{PV}^{34}$. La demostración de los niveles de DSG3 marcadamente reducidos en el epitelio corneal en el PV en comparación con la córnea normal, así como la identificación de autoanticuerpos contra IgG4 en el epitelio corneal, indican que el involucro corneal en el PV está mediado en parte 0 en su totalidad por autoanticuerpos contra DSG3. Esto está en línea con la presencia de autoanticuerpos anti-DSG3 circulantes en pacientes con PV ${ }^{35}$.
Algunos han sugerido que la baja incidencia de hallazgos oculares asociados con el PV se debe a la capacidad de las proteínas que no son desmogleínas para compensar la pérdida de la función de DSG3 causada por los autoanticuerpos anti-DSG en el PV ${ }^{9}$.La expresión de varias proteínas DSG también puede disminuir la probabilidad de desarrollar patología corneal mediada por anti-DSG, ya que se espera que las DSG no afectadas mantengan la integridad del epitelio y, por lo tanto, compensen la pérdida de cualquier DSG individual ${ }^{36,37}$. La llamada teoría de la compensación de las desmogleínas puede explicar la incidencia extremadamente baja de afectación corneal en el PV y en otras enfermedades mediadas por anti-DSG. Aunque demostramos que las cuatro proteínas DSG están presentes en el epitelio corneal, describimos un fenotipo corneal pronunciado en el caso que 


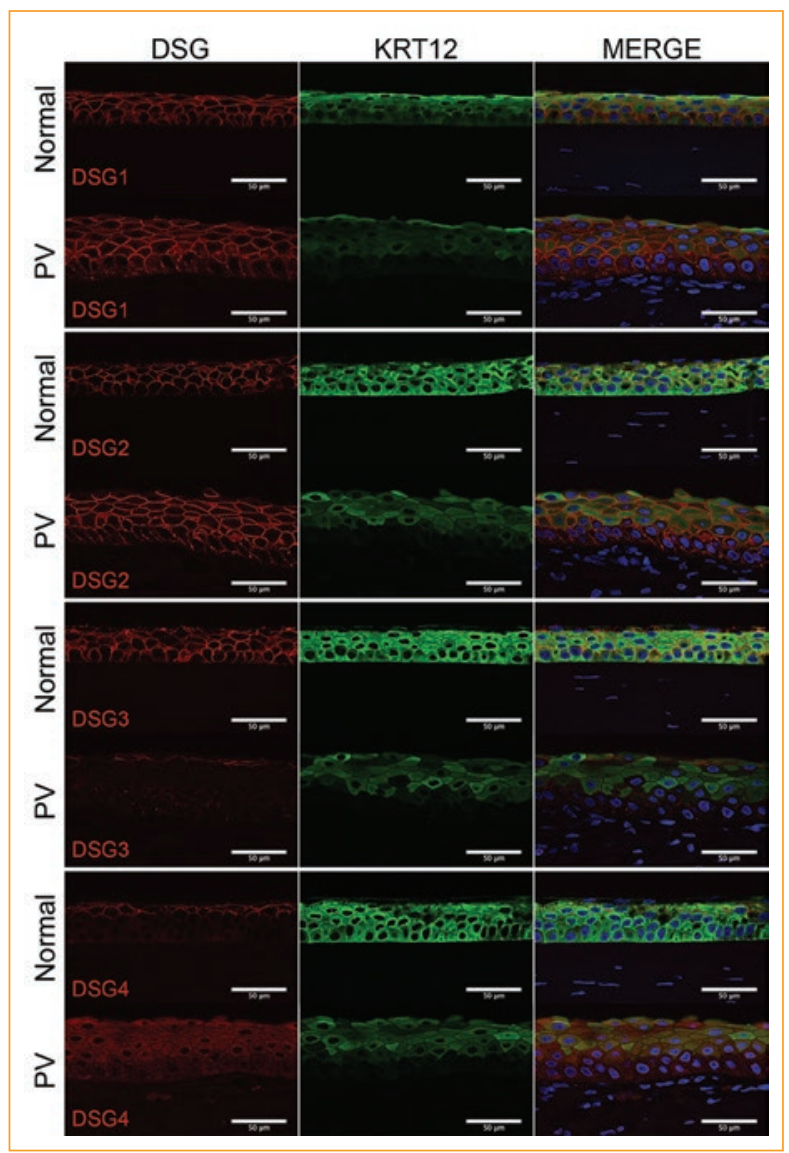

Figura 5. Evaluación de la expresión de proteínas DSG1-4 en el tejido corneal donante y con PV mediante inmunohistoquímica con fluorescencia. Primera columna: en el epitelio corneal del donante (normal), se detectaron las cuatro proteínas DSG (rojas) en los contactos célulacélula; en el epitelio corneal con PV, DSG1 y 2 demostraron una expresión similar a la del control, pero la expresión de DSG3 y DSG4 estaba disminuida. Segunda columna: la expresión epitelial corneal de KRT12 (verde), un biomarcador específico del epitelio corneal, se utilizó como control positivo. Tercera columna: se aplicó contra tinción de las secciones de tejido con DAPI (azul; núcleo celular). Barra de escala $=50 \mathrm{~mm}$.

PV: pénfigo vulgar.

presentamos. Estos datos sugieren que el mecanismo que resulta en la fisiopatología en el paciente que describimos, es más complejo y puede incluir un componente que supere el presunto efecto protector de la expresión de varias DSG. Si bien la baja incidencia de hallazgos corneales en el PV puede apoyar indirectamente la teoría de la compensación de las desmogleínas, el caso que presentamos puede ser un ejemplo que refuta la teoría, o al menos una excepción.

Una segunda barrera para el involucro corneal es que la córnea es normalmente avascular, lo que limita la capacidad de las células inmunes y las inmunoglobulinas

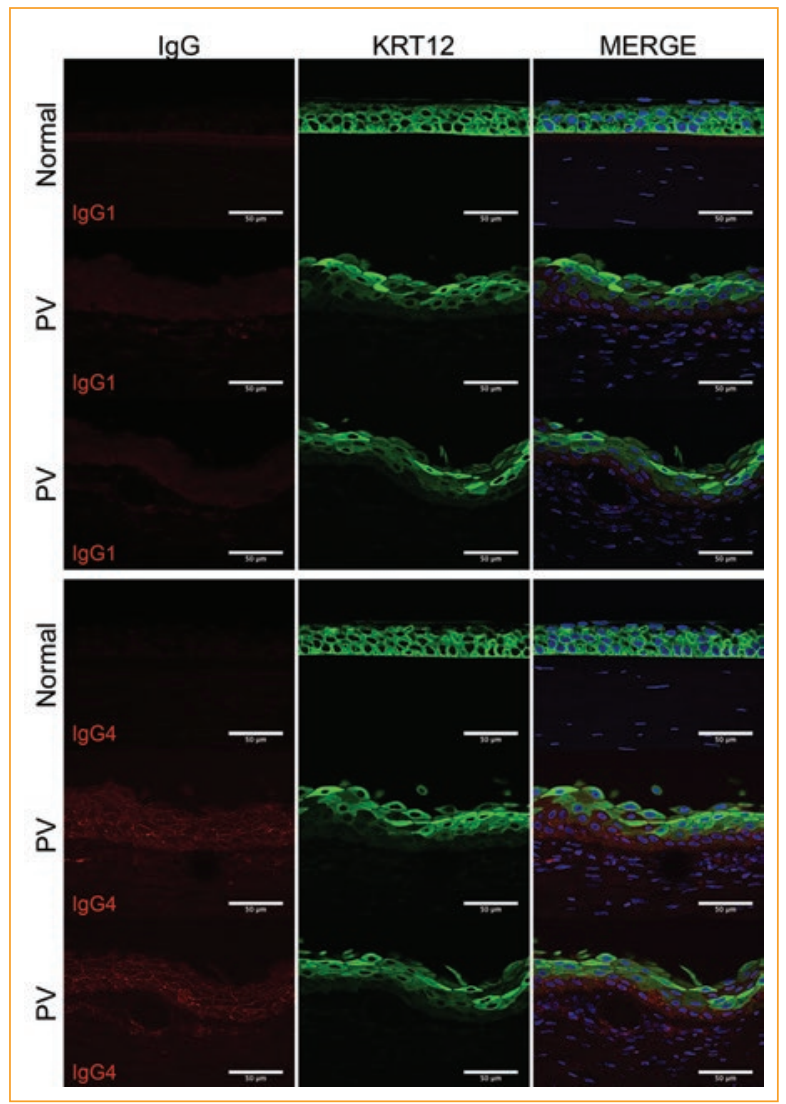

Figura 6. La localización de las inmunoglobulinas G1 y G4 en la córnea con PV se determinó mediante F-IHQ. Primera columna: en el epitelio corneal del donante (normal), no se detectaron IgG1 ni IgG4 (rojo); en el epitelio corneal con PV, no se visualizó IgG1, mientras que IgG4 se localizó en los contactos célula-célula. Segunda columna: la expresión epitelial corneal de KRT12 (verde), un biomarcador específico del epitelio corneal, se utilizó como control positivo. Tercera columna: se aplicó contra tinción de las secciones de tejido con DAPI (azul; núcleo celular). Barra de escala $=50 \mathrm{~mm}$.

PV: pénfigo vulgar.

para infiltrarse en la córnea. El paciente que informamos tenía ojos rojos crónicos desde la infancia (según los antecedentes), lo que posiblemente resultó en la neovascularización corneal evidente en el momento de la presentación. La pérdida de la avascularidad corneal permitiría que las inmunoglobulinas se localicen en el epitelio corneal y superen el efecto protector de otras DSG presentes.

\section{Conclusiones}

Aunque el PV afecta principalmente la piel y la mucosa oral, el epitelio corneal también puede verse afectado. Aquí demostramos la expresión de DSG alterada en el epitelio corneal con PV y la localización de IgG4 
en los contactos célula-célula en el epitelio corneal con $\mathrm{PV}$, proporcionando un mecanismo fisiopatológico para estas características corneales inusuales pero prominentes. Por lo tanto, en ausencia de cualquier causa secundaria identificable, la patología corneal asociada con el PV probablemente está mediada por autoanticuerpos dirigidos contra DSG3 en el epitelio corneal. También demostramos la expresión corneal de los cuatro genes de DSG y proporcionamos una visión general integral de la expresión de DSG en el epitelio corneal.

\section{Responsabilidades éticas}

Protección de personas y animales. Los autores declaran que los procedimientos seguidos se conformaron a las normas éticas del comité de experimentación humana responsable y de acuerdo con la Asociación Médica Mundial y la Declaración de Helsinki.

Confidencialidad de los datos. Los autores declaran que han seguido los protocolos de su centro de trabajo sobre la publicación de datos de pacientes.

Derecho a la privacidad y consentimiento informado. Los autores han obtenido el consentimiento informado de los pacientes y/o sujetos referidos en el artículo. Este documento obra en poder del autor de correspondencia.

\section{Financiación}

Apoyo proporcionado por los fondos del National Eye Institute R01 EY022082 (A.J.A), P30 EY000331 (subvención básica al Stein Eye Institute) y una subvención sin restricciones de "Research to Prevent Blindness" (Stein Eye Institute).

\section{Bibliografía}

1. Korman N. Pemphigus. J Am Acad Dermatol. 1988;18:1219-1238.

2. Daoud YJ, Cervantes R, Foster CS, et al. Ocular pemphigus. J Am Acad Dermatol. 2005:53:585-590.

3. Laforest C, Huilgol SC, Casson R, et al. Autoimmune bullous diseases: ocular manifestations and management. Drugs. 2005;65:1767-1779.

4. Santoro FA, Stoopler ET, Werth VP. Pemphigus. Dent Clin North Am. 2013;57:597-610.

5. Anan T, Shimizu F, Hatano Y, et al. Paraneoplastic pemphigus associated with corneal perforation and cutaneous alternariosis: a case report and review of cases treated with rituximab. J Dermatol. 2011:38:1084-1089.

6. Joly P, Richard C, Gilbert D, et al. Sensitivity and specificity of clinical, histologic, and immunologic features in the diagnosis of paraneoplastic pemphigus. J Am Acad Dermatol. 2000;43:619-626.

7. Akhyani M, Keshtkar-Jafari A, Chams-Davatchi C, et al. Ocular involvement in pemphigus vulgaris. J Dermatol. 2014;41:618-621.

8. Esmaili N, Chams-Davatchi C, Valikhani M, et al. Pemphigus vulgaris in Iran: a clinical study of 140 cases. Int J Dermatol. 2007;46:1166-1170.
9. Olszewska M, Komor M, Mazur M, et al. Response of ocular pemphigus vulgaris to therapy. Case report and review of literature. J Dermatol Case Rep. 2008;2:1-3.

10. Palleschi GM, Giomi B, Fabbri P. Ocular involvement in pemphigus. $A m$ $J$ Ophthalmol. 2007;144:149-152.

11. Hodak E, Kremer I, David M, et al. Conjunctival involvement in pemphigus vulgaris: a clinical, histopathological and immunofluorescence study. $\mathrm{Br} \mathrm{J}$ Dermatol. 1990;123:615-620.

12. Baykal HE, Pleyer U, Sonnichsen K, et al. [Severe eye involvement in pemphigus vulgaris]. Ophthalmologe. 1995;92:854-857.

13. Lifshitz T, Levy J, Cagnano E, et al. Severe conjunctival and eyelid involvement in pemphigus vulgaris. Int Ophthalmol. 2004;25:73-74.

14. Suami M, Kato M, Koide K, et al. Keratolysis in a patient with pemphigus vulgaris. Br J Ophthalmol. 2001:85:1263-1264.

15. Chirinos-Saldana P, Zuniga-Gonzalez I, Hernandez-Camarena JC, et al. Cicatricial changes in ocular pemphigus. Eye (Lond). 2014;28:459-465.

16. Wang X, Seed B. A PCR primer bank for quantitative gene expression analysis. Nucleic Acids Res. 2003;31:e154.

17. Spandidos $A$, Wang $X$, Wang $H$, et al. A comprehensive collection of experimentally validated primers for Polymerase Chain Reaction quantitation of murine transcript abundance. BMC Genomics. 2008;9:633.

18. Spandidos A, Wang $X$, Wang $H$, et al. PrimerBank: a resource of human and mouse PCR primer pairs for gene expression detection and quantification. Nucleic Acids Res. 2010;38:D792-799.

19. Kim MJ, Frausto RF, Rosenwasser GO, et al. Posterior Amorphous Corneal Dystrophy Is Associated with a Deletion of Small Leucine-rich Proteoglycans on Chromosome 12. PLoS One. 2014;9:e95037.

20. Delva E, Tucker DK, Kowalczyk AP. The desmosome. Cold Spring Harb Perspect Biol. 2009;1:a002543.

21. Rubinstein N, Stanley JR. Pemphigus foliaceus antibodies and a monoclonal antibody to desmoglein I demonstrate stratified squamous epithelial-specific epitopes of desmosomes. Am J Dermatopathol. 1987;9:510-514.

22. Kapprell HP, Owaribe K, Franke WW. Identification of a basic protein of Mr 75,000 as an accessory desmosomal plaque protein in stratified and complex epithelia. J Cell Biol. 1988;106:1679-1691.

23. Suzuki K, Tanaka T, Enoki M, et al. Coordinated reassembly of the basement membrane and junctional proteins during corneal epithelial wound healing. Invest Ophthalmol Vis Sci. 2000;41:2495-2500.

24. Messent AJ, Blissett MJ, Smith GL, et al. Expression of a single pair of desmosomal glycoproteins renders the corneal epithelium unique amongst stratified epithelia. Invest Ophthalmol Vis Sci. 2000;41:8-15.

25. Okada Y, Saika S, Shirai K, et al. Disappearance of desmosomal components in rat corneal epithelium during wound healing. Ophthalmologica. 2001:215:61-65.

26. Davis J, Duncan MK, Robison WG, Jr., et al. Requirement for Pax6 in corneal morphogenesis: a role in adhesion. J Cell Sci. 2003;116:2157-2167.

27. Okada $Y$, Senba E, Shirai K, et al. Perturbed intraepithelial differentiation of corneal epithelium in c-Fos-null mice. Jpn J Ophthalmol. 2008:52:1-7.

28. Kenchegowda D, Harvey SA, Swamynathan S, et al. Critical role of Klf5 in regulating gene expression during post-eyelid opening maturation of mouse corneas. PLoS One. 2012;7:e44771.

29. Hrdlickova-Cela E, Plzak J, Smetana K, Jr., et al. Detection of galectin-3 in tear fluid at disease states and immunohistochemical and lectin histochemical analysis in human corneal and conjunctival epithelium. $\mathrm{Br} J$ Ophthalmol. 2001;85:1336-1340.

30. Nielsen K, Heegaard S, Vorum H, et al. Altered expression of CLC, DSG3, EMP3, S100A2, and SLPI in corneal epithelium from keratoconus patients. Cornea. 2005;24:661-668.

31. Yeung AM, Schlotzer-Schrehardt U, Kulkarni B, et al. Limbal epithelial crypt: a model for corneal epithelial maintenance and novel limbal regional variations. Arch Ophthalmol. 2008;126:665-669.

32. Gonzalez-Andrades M, Garzon I, Gascon MI, et al. Sequential development of intercellular junctions in bioengineered human corneas. J Tissue Eng Regen Med. 2009;3:442-449.

33. Plzak J, Smetana K, Jr., Hrdlickova E, et al. Expression of galectin-3-reactive ligands in squamous cancer and normal epithelial cells as a marker of differentiation. Int J Oncol. 2001;19:59-64.

34. Koga H, Tsuruta D, Ohyama B, et al. Desmoglein 3, its pathogenecity and a possibility for therapeutic target in pemphigus vulgaris. Expert Opin Ther Targets. 2013;17:293-306.

35. Narbutt J, Boncela J, Smolarczyk K, et al. Pathogenic activity of circulating anti-desmoglein-3 autoantibodies isolated from pemphigus vulgaris patients. Arch Med Sci. 2012:8:347-356.

36. Amagai M. Autoimmunity against desmosomal cadherins in pemphigus. J Dermatol Sci. 1999;20:92-102.

37. Pan M, Liu X, Zheng J. The pathogenic role of autoantibodies in pemphigus vulgaris. Clin Exp Dermatol. 2011;36:703-707. 